\title{
Corrigendum: Tofacitinib induction and maintenance therapy in East Asian patients with active ulcerative colitis: subgroup analyses from three phase 3 multinational studies
}

\author{
Satoshi Motoya ${ }^{1}$, Mamoru Watanabe ${ }^{2}$, Hyo Jong Kim ${ }^{3}$, Young Ho Kim ${ }^{4}$, Dong Soo Han ${ }^{5}$, Hirotoshi Yuasa ${ }^{6}$, \\ Junichi Tabira ${ }^{6}$, Naoki Isogawa ${ }^{6}$, Shoko Arai ${ }^{6}$, Isao Kawaguchi ${ }^{6}$, Toshifumi Hibi ${ }^{7}$ \\ ${ }^{1}$ IBD Center, Sapporo Kosei General Hospital, Sapporo, ${ }^{2}$ Department of Gastroenterology and Hepatology, Tokyo Medical and Dental \\ University, Tokyo, Japan, ${ }^{3}$ Division of Gastroenterology, Department of Internal Medicine, Kyung Hee University School of Medicine, Seoul, \\ ${ }^{4}$ Division of Gastroenterology, Department of Medicine, Samsung Medical Center, Sungkyunkwan University School of Medicine, Seoul, \\ ${ }^{5}$ Department of Internal Medicine, Hanyang University Guri Hospital, Guri, Korea, ${ }^{6}$ Inflammation \& Immunology, Pfizer Japan Inc, Tokyo, \\ ${ }^{7}$ Center for Advanced IBD Research and Treatment, Kitasato University, Tokyo, Japan
}

\section{Correction to: \\ https://doi.org/10.5217/ir.2018.16.2.233 \\ Intest Res 2018;16(2):233-245; published April 30, 2018; updated July 30, 2018}

In this article, the authors regret an error in the reporting of Inflammatory Bowel Disease Questionnaire (IBDQ) patientreported outcome data in the manuscript. A data extraction error resulted in incorrect IBDQ data being presented in the publication. The error does not affect the overall conclusions regarding IBDQ as the difference between the corrected and erroneous numbers is, in general, small. The error was specific to IBDQ data; all other data have been reviewed and are correct as originally reported.

The error affected the IBDQ total scores at baseline reported in Table 1 of the manuscript, and the IBDQ data reported in Section 3. Patient-Reported Outcomes of the manuscript. The corrected IBDQ data for Table 1 and Section 3. Patient-Reported Outcomes are reported below. The corrigendum does not change the conclusion of the article.

\section{The original text read as follows:}

\section{Patient-Reported Outcomes}

\section{1) Patient-Reported Outcomes in OCTAVE Induction 1 and 2}

The baseline (SD) mean IBDQ total score was 129.0 (29.4) in the placebo group and 135.8 (28.9) in the tofacitinib $10 \mathrm{mg}$ BID group. Treatment with tofacitinib $10 \mathrm{mg}$ BID resulted in numerically greater improvements from baseline versus placebo in the IBDQ total score and in all IBDQ domain scores at weeks 4 and 8 . The mean change from baseline in total IBDQ score with tofacitinib $10 \mathrm{mg}$ BID was 22.5 at week 4 and 27.4 at week 8 . The respective values with placebo were 11.5 and 14.9 . For the Bowel Function Score, the week 8 mean change from baseline was 10.6 with tofacitinib $10 \mathrm{mg}$ BID versus 6.6 with placebo (week 4: 8.5 vs. 4.7, respectively). For the Emotional Status Score, the mean changes from baseline were 7.5 versus 5.0 at week 8 and 6.6 versus 4.6 at week 4 for tofacitinib $10 \mathrm{mg}$ BID and placebo, respectively. The respective changes from baseline in the Systemic 
Symptoms Score were 4.3 versus 2.1 at week 8 and 3.3 versus 0.9 at week 4. For the Social Function Score, the changes from baseline were 5.1 versus 1.2 at week 8 and 4.1 versus 1.3 at week 4 in the tofacitinib and placebo groups, respectively. IBDQ remission at week 8 was achieved by $56.8 \%$ of tofacitinib-treated patients versus $15.4 \%$ of patients with placebo (44.2\% vs. $19.2 \%$ at week 4), and IBDQ response at week 8 was achieved by $62.1 \%$ of tofacitinib-treated patients versus $38.5 \%$ of those with placebo (55.8\% vs. $34.6 \%$ at week 4$)$.

\section{2) Patient-Reported Outcomes in OCTAVE Sustain}

The mean (SD) IBDQ score at baseline of OCTAVE Sustain was 164.0 (26.8) in the placebo group, 174.0 (10.9) in the tofacitinib $5 \mathrm{mg}$ BID group, and 166.4 (18.8) in the tofacitinib $10 \mathrm{mg}$ BID group. The mean changes from baseline in the total IBDQ score at week 52 of OCTAVE Sustain were 3.1 with tofacitinib $5 \mathrm{mg}$ BID and 9.9 with tofacitinib $10 \mathrm{mg}$ BID, compared with -1.0 with placebo. The mean changes from baseline in the Bowel Function Score at week 52 were -0.8 with tofacitinib 5 mg BID, 3.4 with tofacitinib $10 \mathrm{mg}$ BID, and 0.8 with placebo. For the Emotional Status Score, the week 52 mean changes from baseline were 3.4 and 3.0 with tofacitinib $5 \mathrm{mg}$ BID and $10 \mathrm{mg}$ BID, respectively, versus -1.3 with placebo. For the Systemic Symptoms Score, the mean changes from baseline at week 52 were 0.3 with tofacitinib $5 \mathrm{mg}$ BID, 1.5 with tofacitinib $10 \mathrm{mg}$ BID, and -0.8 with placebo. For the Social Function Score, the week 52 changes from baseline were 0.1 and 2.1 with tofacitinib $5 \mathrm{mg}$ BID and $10 \mathrm{mg}$ BID, respectively, and 0.3 with placebo. At week 52 of OCTAVE Sustain, $50.0 \%$ of patients in the tofacitinib $5 \mathrm{mg}$ BID group, $42.9 \%$ of patients in the tofacitinib $10 \mathrm{mg}$ BID group, and $15.0 \%$ of patients in the placebo group achieved IBDQ remission. IBDQ response at week 52 was achieved by $40.9 \%$ and $52.4 \%$ of patients receiving tofacitinib $5 \mathrm{mg}$ BID and tofacitinib 10 $\mathrm{mg}$ BID, respectively, versus $30.0 \%$ of patients receiving placebo.

\section{The revised text now reads:}

\section{Patient-Reported Outcomes}

\section{1) Patient-Reported Outcomes in OCTAVE Induction 1 and 2}

The baseline (SD) mean IBDQ total score was $\underline{132.7(31.6)}$ in the placebo group and $\underline{134.9(36.0)}$ in the tofacitinib $10 \mathrm{mg}$ BID group. Treatment with tofacitinib $10 \mathrm{mg}$ BID resulted in numerically greater improvements from baseline versus placebo in the IBDQ total score and in all IBDQ domain scores at weeks 4 and 8 . The mean change from baseline in total IBDQ score with tofacitinib $10 \mathrm{mg}$ BID was $\underline{30.1}$ at week 4 and $\underline{37.2}$ at week 8 . The respective values with placebo were 11.5 and $\underline{18.2}$. For the Bowel Function Score, the week 8 mean change from baseline was $\underline{15.0}$ with tofacitinib $10 \mathrm{mg}$ BID versus $\underline{6.5}$ with placebo (week $4: \underline{11.9}$ vs $\underline{4.4}$, respectively). For the Emotional Status Score, the mean changes from baseline were $\underline{10.8}$ versus $\underline{6.3}$ at week 8 and 8.8 versus $\underline{3.7}$ at week 4 for tofacitinib $10 \mathrm{mg}$ BID and placebo, respectively. The respective changes from baseline in the Systemic Symptoms Score were $\underline{5.2}$ versus $\underline{3.9}$ at week 8 and $\underline{4.1}$ versus $\underline{2.3}$ at week 4 . For the Social Function Score, the changes from baseline were $\underline{6.3}$ versus $\underline{1.6}$ at week 8 and $\underline{5.3}$ versus $\underline{1.2}$ at week 4 in the tofacitinib and placebo groups, respectively. IBDQ remission at week 8 was achieved by $\underline{61.1 \%}$ of tofacitinib-treated patients versus $\underline{23.1 \%}$ of patients with placebo $\underline{\underline{50.5 \%}}$ vs. $\underline{26.9 \%}$ at week 4), and IBDQ response at week 8 was achieved by $\underline{71.6 \%}$ of tofacitinib-treated patients versus $\underline{42.3 \%}$ of those with placebo ( $\underline{68.4 \%}$ vs. $\underline{42.3 \%}$ at week 4$)$.

\section{2) Patient-Reported Outcomes in OCTAVE Sustain}

The mean (SD) IBDQ score at baseline of OCTAVE Sustain was 176.2 (28.7) in the placebo group, 189.8 (23.1) in the tofacitinib $5 \mathrm{mg}$ BID group, and $\underline{180.6(25.0)}$ in the tofacitinib $10 \mathrm{mg}$ BID group. The mean changes from baseline in the total IBDQ score at week 52 of OCTAVE Sustain were $\underline{-0.3}$ with tofacitinib $5 \mathrm{mg}$ BID and $\underline{11.4}$ with tofacitinib $10 \mathrm{mg}$ BID, compared with 8.2 with placebo. The mean changes from baseline in the Bowel Function Score at week 52 were -0.8 with tofacitinib $5 \mathrm{mg}$ BID, $\underline{2.6}$ with tofacitinib $10 \mathrm{mg}$ BID, and $\underline{1.9}$ with placebo. For the Emotional Status Score, the week 52 mean changes from baseline were $\underline{0.3}$ and $\underline{4.3}$ with tofacitinib $5 \mathrm{mg}$ BID and $10 \mathrm{mg}$ BID, respectively, versus $\underline{2.4}$ with placebo. For the Systemic Symptoms Score, the mean changes from baseline at week 52 were $\underline{-0.1}$ with tofacitinib $5 \mathrm{mg}$ BID, $\underline{2.4}$ with tofacitinib $10 \mathrm{mg}$ BID, and $\underline{0.4}$ with placebo. For the Social Function Score, the week 52 changes from baseline were $\underline{0.4}$ and 2.1 with tofacitinib $5 \mathrm{mg}$ BID and $10 \mathrm{mg}$ BID, respectively, and $\underline{3.4}$ with placebo. At week 52 of OCTAVE Sustain, $\underline{63.6 \%}$ of patients in the tofacitinib $5 \mathrm{mg}$ BID 
group, $\underline{61.9 \%}$ of patients in the tofacitinib $10 \mathrm{mg}$ BID group, and $\underline{40.0 \%}$ of patients in the placebo group achieved IBDQ remission. IBDQ response at week 52 was achieved by $\underline{59.1 \%}$ and $\underline{61.9 \%}$ of patients receiving tofacitinib 5 mg BID and tofacitinib 10 mg BID, respectively, versus $30.0 \%$ of patients receiving placebo.

Table 1. Demographics and Baseline Disease Characteristics for the East Asian Population of Patients in OCTAVE Induction 1 and 2 and OCTAVE Sustain, by Treatment Group

The row in Table 1 originally reported the IBDQ total scores at baseline as follows:

\begin{tabular}{|c|c|c|c|c|c|}
\hline \multirow[b]{2}{*}{ Characteristics } & \multicolumn{2}{|c|}{ OCTAVE Induction 1 and 2} & \multicolumn{3}{|c|}{ OCTAVE Sustain } \\
\hline & $\begin{array}{l}\text { Placebo } \\
(n=26)\end{array}$ & $\begin{array}{c}\text { Tofacitinib } \\
10 \mathrm{mg} \mathrm{BID}(n=95)\end{array}$ & $\begin{array}{l}\text { Placebo } \\
(n=20)\end{array}$ & $\begin{array}{c}\text { Tofacitinib } \\
5 \mathrm{mg} \mathrm{BID}(\mathrm{n}=22)\end{array}$ & $\begin{array}{c}\text { Tofacitinib } \\
10 \mathrm{mg} \mathrm{BID}(\mathrm{n}=21)\end{array}$ \\
\hline
\end{tabular}

The revised data now reads:

\begin{tabular}{|c|c|c|c|c|c|}
\hline \multirow[b]{2}{*}{ Characteristics } & \multicolumn{2}{|c|}{ OCTAVE Induction 1 and 2} & \multicolumn{3}{|c|}{ OCTAVE Sustain } \\
\hline & $\begin{array}{l}\text { Placebo } \\
(n=26)\end{array}$ & $\begin{array}{c}\text { Tofacitinib } \\
10 \mathrm{mg} \text { BID }(n=95)\end{array}$ & $\begin{array}{l}\text { Placebo } \\
(n=20)\end{array}$ & $\begin{array}{c}\text { Tofacitinib } \\
5 \mathrm{mg} \mathrm{BID}(n=22)\end{array}$ & $\begin{array}{c}\text { Tofacitinib } \\
10 \mathrm{mg} \mathrm{BID}(\mathrm{n}=21)\end{array}$ \\
\hline
\end{tabular}

